\title{
Pelatihan Agro Eco-System Analysis Petani Ketela Pohon dalam Teknik Pengelolaan Organisme Pengganggu Tanaman
}

\author{
Sri Wahyuni ${ }^{1}$, Willybrordus Lanamana ${ }^{1}$, Kristono Y. Fowo ${ }^{1}$ \\ Lourentius D. Gadi Djou², Yohanes Pande ${ }^{3}$ \\ ${ }^{1}$ Program Studi Agroteknologi Fakultas Pertanian Universitas Flores \\ ${ }^{2}$ Program Studi Akuntansi Fakultas Ekonomi Universitas Flores \\ ${ }^{3}$ Program Studi Ilmu Hukum, Fakultas Hukum, Universitas Flores \\ Jln.Sam Ratulangi XX-Paupire, Kabupaten Ende Propinsi Nusa Tenggara Timur \\ *Correspoding Author : sriwahyuni4611@gmail.com \\ Dikirim: 19-10-2021 Diterima: 31-12-2021
}

\begin{abstract}
ABSTRAK
Fluktuasi populasi hama dan penyakit di pertanaman ketela pohon cenderung meningkat dan penyebarannya sangat cepat pada kondisi kebun yang kering dan pola tanam monokultur dengan jarak tanam yang rapat, sehingga keberadaan organisme pengganggu tanaman (OPT) di pertanaman sangat tergantung pada kondisi agroekosistem. Pengendalian OPT berbasis ekologis merupakan suatu keniscayaan dalam menjaga kestabilan ekosistem pertanaman, maka dibutuhkan kemampuan dasar dalam melakukan analisis agroekosistem/Agro Eco-System Analysis (AESA). Berdasarkan hasil kegiatan AESA didapatkan rekomendasi pengelolaan ekosistem yang tepat untuk setiap musim tanam dan mempermudah petani dalam menentukan teknik budidaya yang baik berkenaan dengan pengelolaan OPT, pola tanam, konservasi tanah dan air serta musuh alami yang tepat bagi tanamannya. Kegiatan AESA dilakukan agar petani mampu memahami dan terampil dalam mengelola kebun ketela pohonnya karena Desa Randotonda sebagai daerah penghasil ketela pohon "Nuabosi" yang dikenal sebagai produk unggulan daerah. Kegiatan dilakukan secara partisipatif dengan melibatkan langsung petani peserta sebagai pengamat, pencari fakta dan pengambil keputusan bagi pengelolaan agroekosistemnya melalui diskusi dan memanifestasikan kondisi riil saat ini dengan harapan ke depan dapat melakukan pengelolaan agroekosistem pertanamannya dengan baik. Peningkatan pemahaman petani tertinggi terjadi pada komponen musuh alami sebesar 91,67\% sedangkan rata-rata peningkatan pemahaman petani untuk seluruh komponen agroekosistem sebesar $57,14 \%$. Seluruh peserta mampu melakukan AESA dengan sangat baik yang ditandai dengan kemampuan petani dalam menyusun rekomendasi pengelolaan agroekosistem ketela pohon untuk musim tanam berikutnya.
\end{abstract}

Kata kunci: parasitoid, predator, tumpang sari.

\section{Training on Agro Eco-System Analysis for Cassava Farmers in Plant Pest Organism Management Techniques}

\begin{abstract}
Pest population fluctuations in cassava plants tend to increase and spread rapidly in drought fields and a monoculture cropping pattern with close spacing therefore the presence of pests planted is highly dependent on agro-ecosystem conditions. Therefore ecological-based pest control is very necessary. To maintain the stability of the plant ecosystem, basic skills are needed in conducting agroecosystem analysis (AESA). Based on the analysis results obtained recommendations for appropriate ecosystem management for each growing season and facilitate farmers in determining good cultivation techniques regarding pest control, cropping patterns, soil and water conservation as well as natural enemies that are appropriate for their plants. AESA activities are carried out so that farmers understand and are skilled in managing their cassava plantations because Randotonda Village is a producer of "Nuabosi" cassava which is known as a regional superior product. The
\end{abstract}


activity is carried out in a participatory manner by directly involving the participating farmers as observers, fact seekers and decision-makers for the management of their agroecosystems through discussion and manifesting current real conditions with the hope that in the future they can manage their cropping agroecosystems properly. The highest increase in farmer understanding occurred in natural enemy components of $91.67 \%$ while the average increase in farmer understanding for all agro-ecosystem components was $57.14 \%$. All participants were able to perform AESA very well which was indicated by the ability of farmers to make recommendations for managing cassava agroecosystems for the next planting season.

Keywords: parasitoid, predator, intercropping

\section{PENDAHULUAN}

Pemahaman dasar tentang keseimbangan ekosistem dibutuhkan untuk menjaga keberlanjutan ekosistem kebun termasuk di dalamnya adalah tindakan pengelolaan organisme pengganggu tanaman (OPT). Ekosistem yang seimbang adalah ekosistem yang jumlah komponen-komponen penyusunannya berimbang (Effendi et al., 2018) dan terjadi interaksi pada setiap komponen sehingga aliran energi berjalan secara berkelanjutan (Wulandari, 2016). Ekosistem pertanaman yang dimaksud meliputi ekosistem tanah dan tanaman. Kerusakan ekosistem tanah dapat dilihat dari kondisi fisik dan biologi tanah yang mengalami penurunan kualitas dan kuantitas yaitu berkurangnya unsur hara dan mikroorganisme dalam tanah (Wahyunto \& Dariah, 2014) sebagai akibat adanya perlakuan sistem pertanian yang diterapkan oleh petani. Sedangkan ekosistem tanaman menyangkut kondisi mikro di pertanaman yang dapat menghambat pertumbuhan tanaman dan menguntungkan bagi perkembangan OPT. Pemahaman petani tentang pengelolaan agroekosistem kebun ketela pohon masih tergolong rendah.

Akibat pengelolaan agroekosistem yang tidak tepat maka terjadi penurunan produksi dari tahun-ketahun seperti yang dilaporkan oleh Pemda Ende (2017) dimana produksi ketela pohon tahun 2015 sebesar $116,6 \mathrm{~kg} / \mathrm{ha}$, tahun 2016 sebesar $120 \mathrm{~kg} / \mathrm{ha}$ dan tahun 2018 sebesar $35 \mathrm{~kg} / \mathrm{ha}$. Selain itu, pada tahun 2018 juga diketahui adanya serangan hama kutu putih Phenacoccus manihoti yang menimbulkan kerusakan pada pucuk daun dengan gejala "Banchi top" yaitu terjadi mal bentuk pada pucuk daun. Kemunculan hama ini mengindikasikan adanya kondisi ekosistem yang terganggu. Hasil survei diketahui bahwa budidaya ketela pohon masih dilakukan dengan pola tanam monokultur sepanjang tahun.
Penerapan pola tanam monokultur sangat berpotensi memunculkan OPT baru serta menurunkan kesuburan tanah dan akhirnya dapat berpengaruh pada produktivitas lahan pertanian (Purnomo, 2014).

Menanggapi permasalahan tersebut maka Universitas Flores melalui Program Pengembangan Desa Mitra memberikan solusi berupa peningkatan produksi ketela pohon melalui perbaikan teknik budidaya serta pengelolaan hama dan penyakit. Salah satu kegiatannya adalah dengan melatih penerapan teknik AESA (Agro-Ecosystem Analysis) bagi petani sebagai langkah dasar dalam mengelola organisme pengganggu tanaman berbasis pemberdayaan komponen ekosistem.

Organisme pengganggu tanaman (OPT) dari golongan hama, patogen penyebab penyakit dan gulma merupakan komponen ekosistem yang status keberadaannya di pertanaman ditentukan oleh tinggi dan rendahnya populasi dan tingkat kerusakan yang diakibatkan pada tanaman budidaya. Namun demikian, OPT sebagai komponen ekosistem tentunya juga memiliki peranan dalam menyumbangkan aliran energi dalam menjaga kestabilan ekosistem (Syarief \& Tripama, 2013). Oleh sebab itu konsep pengelolaan OPT lebih tepat jika dibandingkan dengan konsep pengendalian. Pengelolaan OPT adalah suatu tindakan preventif yang mengontrol populasi OPT agar tidak melewati batas ambang ekonomi tanpa harus memusnahkan OPT dari pertanaman sehingga organisme tersebut tetap menjalankan perannya sebagai penyumbang energi pada ekosistem.

Kegiatan AESA bermuara pada pentingnya menciptakan keseimbangan antara herbivora dan musuh alaminya melalui usaha peningkatan keragaman hayati. Peningkatan keragaman vegetasi dan penambahan biomassa menurut Nurindah (2006) dapat meningkatkan indeks keragaman hayati dalam suatu agroekosistem baik di atas maupun di dalam 
tanah. Peningkatan indeks keragaman vegetasi dapat dilakukan melalui penerapan polikultur dengan pengaturan pola tanam yang optimal (Siagian et al., 2019). Peningkatan biomassa dapat dilakukan dengan menambahkan pupuk hijau dan pupuk kandang (Purnomo, 2014), kedua cara tersebut bermuara pada peningkatan produktivitas lahan, kesehatan serta keberkelanjutan ekosistem. Sehubungan dengan rendahnya pemahaman petani dalam pengelolaan agroekosistem maka tujuan utama dari kegiatan ini adalah untuk memberikan pemahaman yang baik kepada petani dan keterampilan menganalisa kondisi pertanaman dengan prinsip pengelolaan agroekosistem untuk pengendalian hama.

\section{METODE}

Pelatihan teknik pengendalian OPT tanaman ketela pohon melalui penguasaan analisis agroekosistem merupakan bagian dari rangkaian kegiatan pada Program Pengembangan Desa Mitra (PPDM) dari Kemendikbudristek yang dimulai pada bulan April - Oktober 2020 di Desa Randotonda Kecamatan Nuabosi. Kegiatan ini terkonsentrasi pada pengembangan kelompok tani ketela pohon dan kelompok ibu-ibu PKK dalam menunjang pengembangan komoditas ketela pohon sebagai komoditi unggulan daerah.

Pelaksanaan pelatihan AESA melalui tahapan sebagai berikut:

1. Pembuatan pertanyaan arahan sebagai acuan dalam melakukan AESA di pertanaman yang mencakup semua komponen agroekosistem.

2. Pengisian pre-test untuk mengukur pengetahuan dan keterampilan petani sebelum melakukan AESA (Gambar 1) yang selanjutnya nanti akan dibandingkan dengan hasil post-tes

3. Praktek AESA dilakukan oleh seluruh peserta dari 18 orang dari kelompok tani dan 16 dari kelompok PKK dengan mengikuti pertanyaan arahan dari tim PKM (Gambar 2)

4. Hasil AESA didiskusikan dalam kelompok untuk memetakan masalah-masalah yang telah ditemukan di pertanaman dan membuat solusinya (Gambar 3)

5. Hasil pekerjaan kelompok akan dipresentasikan dan dibahas bersama dengan tim PKM yang selanjutnya dibuat rekomendasi pengelolaan OPT pada pertanaman (Gambar 4)

6. Kegiatan pelatihan diakhiri dengan pengisian post-tes untuk mengukur peningkatan pemahaman dan keterampilan AESA peserta.

7. Pengukuran peningkatan pemahaman dilakukan dengan menggunakan metode perhitungan statistik sederhana yaitu dengan menghitung persentase perbandingan nilai hasil pre-test dan posttest.

8. Evaluasi kegiatan dilakukan dengan FGD untuk mengetahui tingkat kemanfaatan pelatihan dan rencana tindak lanjut kegiatan berdasarkan rekomendasi yang disusun.

\section{HASIL DAN PEMBAHASAN}

Peningkatan Pengetahuan Petani tentang
Komponen Ekosistem dan Pengelolaan OPT

Konsep pengelolaan merupakan hal yang krusial dalam tindakan pengelolaan OPT pada suatu pertanaman. Tindakan pengelolaan berarti mengelola keberadaan OPT di pertanaman agar populasinya tidak melebihi batas ambang ekonomi.

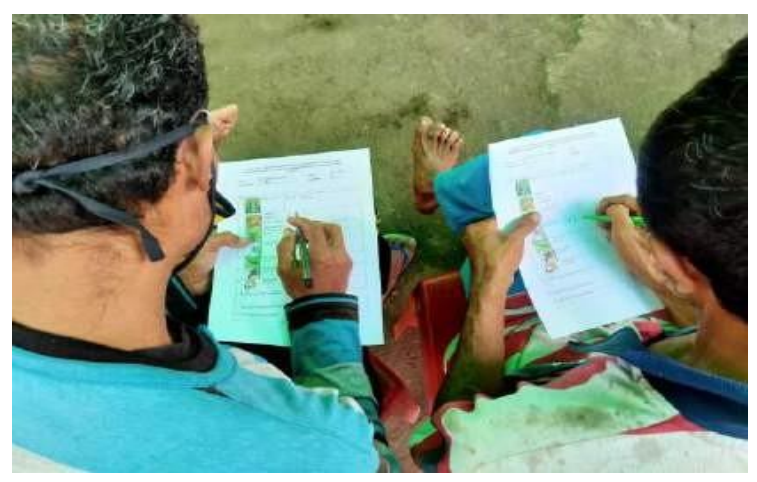

Gambar 1. Pengerjaan pre-test

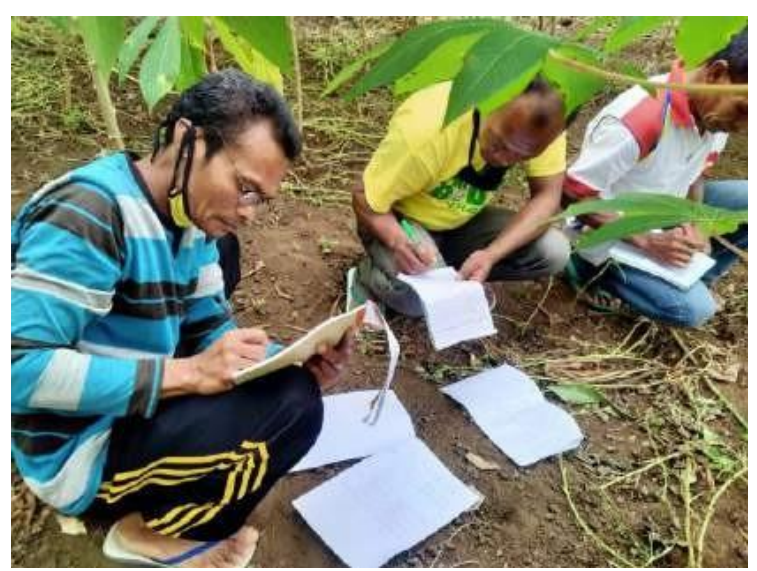

Gambar 2. Petani mengisi petunjuk kerja AESA 


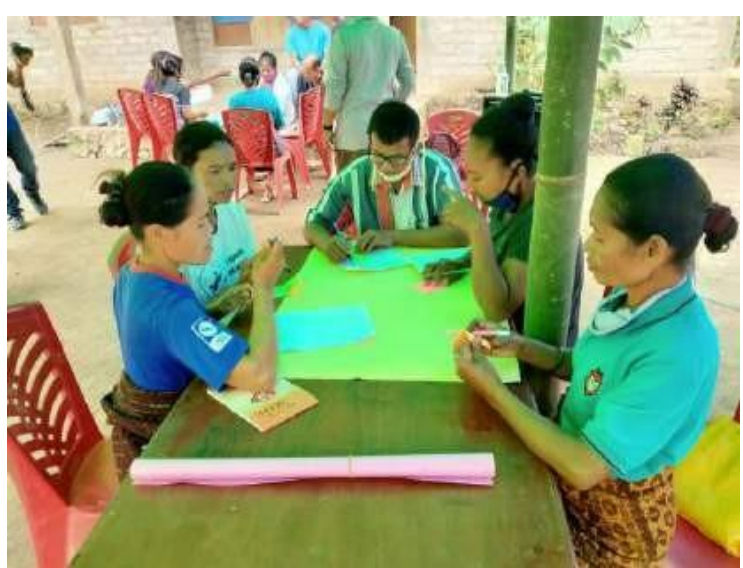

Gambar 3. Diskusi kelompok hasil AESA

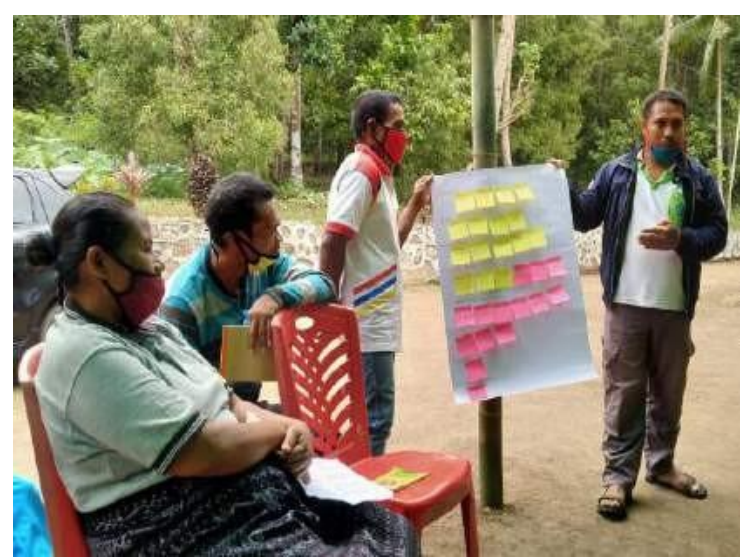

Gambar 4. Presentasi AESA dan rekomendasi

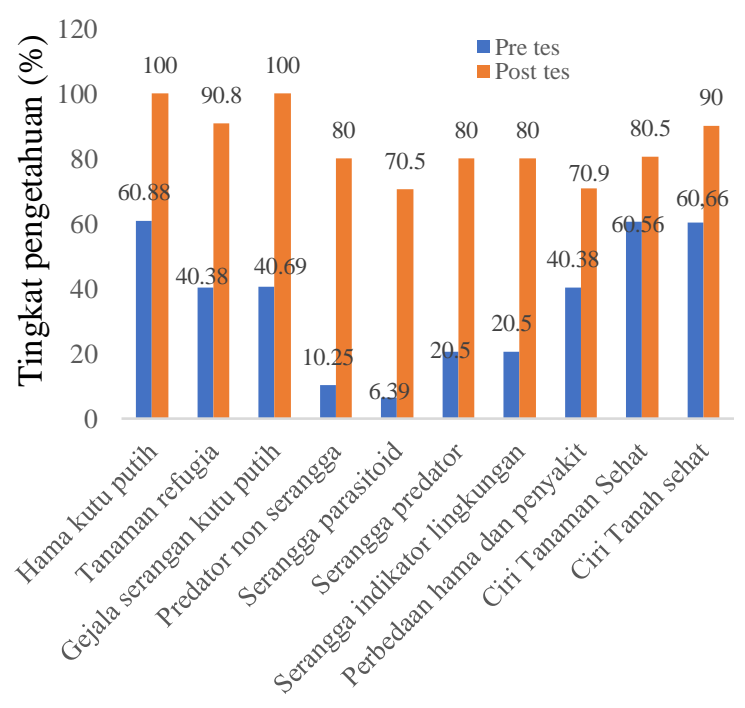

Komponen Ekosistem

Gambar 5. Persentase peningkatan pengetahuan pengelolaan agroekosistem petani setelah pelatihan AESA pada kelompok tani

Sebelum melakukan tindakan pengelolaan seharusnya petani paham komponen pendukung ekosistem dan peranannya dalam menjaga kestabilan ekosistem tersebut. Data pemahaman petani berkaitan tentang komponen ekositem yang ada pada pertanaman serta perannya di alam sebelum dan setelah dilakukan pelatihan AESA (Gambar 5).

Gambar 5 memperlihatkan bahwa ratarata tingkat pengetahuan petani terendah terdapat pada komponen musuh alami baik dari golongan serangga predator $(10,25 \%)$, maupun serangga parasitoid $(6,39 \%)$. Kondisi tersebut mencerminkan bahwa secara umum petani beranggapan bahwa semua jenis serangga adalah hama yang harus dihilangkan dari pertanaman karena akan membawa kerugian bagi tanaman mereka. Namun sesungguhnya keberadaan musuh alami yang berasal dari jenis serangga predator ataupun parasitoid mampu mengontrol populasi hama di pertanaman. Parasitoid dari golongan serangga makan dan hidup dalam larva serangga inang (hama), sedangkan pada fase imago parasitoid memakan nectar dan hidup bebas di alam. Jenis predator dari golongan serangga dan non-serangga seperti laba-laba merupakan jenis pemangsa menyerang dengan cara memburu, memakan, atau menghisap cairan tubuh serangga hama yang menyebabkan kematian pada mangsanya. Jenis serangga predator dan laba-laba merupakan jenis musuh alami (Herlinda et al., 2008) yang berperan penting dalam menekan peningkatan populasi hama di alam (Azima et al., 2017).

Berdasarkan penjelasan dan diperkuat dengan hasil pemantauan AESA yang dilakukan secara langsung oleh petani pada tiga kebun ketela pohon dengan kondisi ekosistem yang berbeda, memberikan pengetahuan dan pemahaman baru terhadap cara pandang petani dalam mengelola pertanamannya. Hasil perhitungan persentase peningkatan pengetahuan petani tertinggi terjadi pada pengetahuan tentang musuh alami sebesar $91,67 \%$ dengan rata-rata peningkatan pengetahuan untuk seluruh komponen ekosistem sebesar 57,14\%. Peningkatan pengetahuan petani tersebut terjadi disebabkan ketidaktahuan petani terhadap keberadaan dan peran musuh alami sebelumnya. Melalui kegiatan AESA yang melibatkan petani secara langsung dan melihat serta membedakan antara musuh alami dan hama menjadikan petani paham bahwa tidak semua serangga adalah hama. Oleh sebab itu, metode pembelajaran partisipatif dengan melibatkan peserta secara langsung dalam proses pengamatan, analisis situasi dan membuat rekomendasi sangat menentukan terjadinya transfer pengetahuan yang efektif (Ibrahim et al., 2019). 
Tabel 1. Hasil analisis dan rekomendasi petani berdasarkan AESA yang dilakukan pada 3 kebun ketela pohon

\begin{tabular}{|c|c|c|}
\hline \multicolumn{3}{|l|}{ Hasil AESA } \\
\hline Kebun I & Kebun II & Kebun III \\
\hline $\begin{array}{l}\text { Cahaya } \\
\text { penuh, ada } \\
\text { tanaman } \\
\text { penutup } \\
\text { tanah, tanah } \\
\text { keras, musuh } \\
\text { alami kurang }\end{array}$ & $\begin{array}{l}\text { Cahaya } \\
\text { penuh, } \\
\text { kondisi } \\
\text { tanah } \\
\text { terbuka dan } \\
\text { kering, } \\
\text { bahan } \\
\text { organik dan } \\
\text { musuh } \\
\text { alami } \\
\text { kurang } \\
\end{array}$ & $\begin{array}{l}\text { Kondisi kebun } \\
\text { sangat lembap, } \\
\text { banyak } \\
\text { tanaman } \\
\text { terserang } \\
\text { penyakit, } \\
\text { pertumbuhan } \\
\text { terhambat, } \\
\text { lahan miring }\end{array}$ \\
\hline \multicolumn{3}{|c|}{ Rekomendasi } \\
\hline Kebun I & Keb & Kel \\
\hline $\begin{array}{l}\text { Perlu } \\
\text { dilakukan } \\
\text { penambahan } \\
\text { bahan } \\
\text { organik dan } \\
\text { menanam } \\
\text { tanaman } \\
\text { refugia } \\
\text { (penghasil } \\
\text { embun } \\
\text { madu) } \\
\text { sebagai } \\
\text { penarik bagi } \\
\text { musuh alami } \\
\text { agar tetap } \\
\text { berada di } \\
\text { pertanaman }\end{array}$ & $\begin{array}{l}\text { Menjaga } \\
\text { kelembapan } \\
\text { tanah } \\
\text { dengan } \\
\text { melakukan } \\
\text { penutupan } \\
\text { tanah atau } \\
\text { menanam } \\
\text { tanaman } \\
\text { sela, } \\
\text { penambahan } \\
\text { bahan } \\
\text { organik dan } \\
\text { penanaman } \\
\text { tanaman } \\
\text { refugia }\end{array}$ & $\begin{array}{l}\text { Pembuatan } \\
\text { terasering yang } \\
\text { lebih luas dan } \\
\text { sesuai dengan } \\
\text { kontur lahan, } \\
\text { penambahan } \\
\text { bahan organik, } \\
\text { tanaman ketela } \\
\text { pohon sebagai } \\
\text { tanaman utama } \\
\text { tidak cocok } \\
\text { maka perlu } \\
\text { mengganti } \\
\text { dengan tanaman } \\
\text { lain yang lebih } \\
\text { tahan naungan }\end{array}$ \\
\hline
\end{tabular}

\section{Kemampuan Petani dalam Melakukan AESA (Agro-Ecosystem Analysis)}

Kegiatan pelatihan AESA ini menjadikan petani sebagai ahli PHT dengan melakukan pengamatan secara langsung pada agroekosistem ketela pohon milik petani yang selanjutnya akan dibuatkan rekomendasi pengelolaan kebun (Tabel 1).

Berdasarkan Tabel 1 maka diketahui bahwa petani telah mampu melakukan AESA. Rekomendasi petani berkenaan dengan kondisi ekosistem dan hubungannya dengan perkembangan hama dan penyakit di pertanaman telah dipahami oleh petani. Hasil diskusi memperlihatkan bahwa petani mulai paham jika hama dan penyakit tidak akan berkembang apabila kondisi lingkungan sehat. Faktor eksternal terutama faktor iklim menjadi salah satu faktor penentu dalam perkembangan dan penyebaran hama dan penyakit di pertanaman. Beberapa hasil penelitian membuktikan bahwa faktor iklim mikro seperti suhu dan kelembapan kebun sangat berpengaruh terhadap perkembangan hama. Kondisi iklim mikro tersebut dapat dimodifikasi dengan mengatur jarak tanam. Kondisi iklim sangat mempengaruhi pertumbuhan populasi kutu Aspidiotus destructor Sign. dimana populasi tinggi terjadi di musim kering dengan kelembapan tinggi (Wardani, 2017). Mengkondisikan iklim mikro pertanaman juga terbukti berpengaruh terhadap perkembangan hama dan penyakit pulai darat (Alstonia angustiloba) dimana jarak tanam yang lebar dapat menekan perkembangan hama dan penyakit lebih tinggi 57\% dibandingkan dengan jarak tanam yang lebih rapat (Asmaliyah \& Rostiwati, 2015). Hasil pengamatan petani memperlihatkan bahwa kebun I dan kebun II memiliki intensitas cahaya matahari dan kelembapan kebun lebih baik dibandingkan kebun III sehingga petani dapat membandingkan kondisi setiap kebun dan menemukan bahwa tanaman yang ditanam di kebun I dan II lebih sehat dibandingkan dengan tanaman di kebun III.

Pengelolaan iklim mikro dan peningkatan produksi tanaman inti melalui pengaturan pola tanam di tingkat petani belum dilakukan secara maksimal, mereka menanam ketela pohon yang dikombinasikan dengan sawi hijau sebagai tanaman antara, namun pada kegiatan kali ini tanaman ketela pohon ditumpangsarikan dengan kacang tanah. Menurut petani, produksi tanaman ketela pohon meningkat setelah mengikuti anjuran tim PPDM. Dari hasil pencatatan tim diketahui bahwa sebelum dilakukan perbaikan pola tanam, produksi rata-rata pertanaman adalah 4-5 umbi dengan berat $0,7-1 \mathrm{~kg} / \mathrm{umbi}$ dan setelah diterapkan pola tanam yang baik maka produksi meningkat menjadi 9-12 umbi/tanaman dengan berat 1-1,7 kg/umbi. Penelitian terdahulu telah membuktikan bahwa sekitar $30 \%$ $\mathrm{N}$ dari hasil fiksasi tanaman kacang-kacangan dapat disumbangkan kepada pertanaman yang ada disekitaranya atau dapat disetarakan dengan adanya penambahan sekitar 5-15 kg N/ha (Nuha et al., 2015; Wijanarko et al., 2009). Sistem tumpang sari juga merupakan teknik pengendalian hama secara budidaya dimana penerapan pola tanam tumpang sari terbukti dapat meningkatkan jumlah musuh alami dan penyerbuk sehingga intensitas serangan hama 
pada ekosistem dapat ditekan (Siagian et al., 2019). Hasil wawancara dengan petani ketela pohon menggambarkan bahwa jumlah serangga yang ada pada pertanaman ketela pohon yang dikombinasikan dengan kacang tanah lebih banyak dibandingkan dengan jumlah serangga pada pertanaman sebelumnya. Kondisi tersebut diduga dapat terjadi karena bunga kacang tanah dapat menyediakan nektar pada seranggaserangga penyerbuk dan parasitoid.

Salah satu rekomendasi yang diusulkan oleh petani pada Tabel 1 adalah penambahan bahan organik. Kondisi kesuburan tanah di Desa Randotonda dijelaskan dalam penelitian Mutiara \& Bolly (2019) yang memperlihatkan bahwa tingkat kesuburan tanah di desa Ndetundora dan Randotonda dalam kategori rendah dengan nilai CEC adalah $37,33 \mathrm{cmol}^{+} / \mathrm{kg}$ (tinggi), BS sebesar $55,34 \%$ (sedang), P sebesar 16,23 ppm (sangat tinggi), $\mathrm{K}$ sebesar $0,69 \mathrm{cmol}^{+} / \mathrm{kg}$ (sangat rendah) dan C-organik sebesar 0,29\% (sangat rendah). Kondisi tanah dengan kandungan $\mathrm{C}$-organik rendah dianjurkan untuk melakukan penambahan bahan organik (Purnomo, 2014). Selain untuk peningkatan produksi, status kesuburan tanah juga berpengaruh terhadap keberadaan OPT di lapangan. Hasil penelitian menjelaskan bahwa tinggi rendahnya status keseburan tanah berpengaruh pada tingkat kesehatan tanaman yang secara langsung juga berpengaruh terhadap populasi tanaman jambu mete yang terserang penyakit blendok dimana semakin tinggi tingkat kesuburan tanah maka semakin rendah populasi tanaman yang sakit (Roidah, 2013; Sulle, 2008).

Rangkaian kegiatan di atas menggambarkan bahwa petani ketela pohon di Desa Randotonda telah paham dan terampil dalam melakukan kegiatan AESA. Keterampilan tersebut digunakan petani untuk memperbaiki kondisi ekosistem ketela pohon pada musim tanam berikutnya. Manfaat lain yang diperoleh dari hasil pengabdian kepada masyarakat (PKM) ini adalah petani menjadi ahli dalam mengelola ekosistem pertanaman mereka untuk menekan populasi OPT di pertanaman.

\section{KESIMPULAN}

Melalui kegiatan PKM ini diketahui terjadi peningkatan pemahaman petani berkenaan dengan komponen agroekosistem tertinggi pada komponen musuh alami sebesar 91,67\% dan rata-rata peningkatan pemahaman petani tentang seluruh komponen agroekosistem sebesar $57,14 \%$. Petani juga sangat terampil dalam membuat rekomendasi perbaikan ekosistem pada pertanaman ketela pohonnya.

\section{UCAPAN TERIMA KASIH}

Ucapan terimakasih penulis sampaikan kepada Kemendikbud-Ristek untuk support pembiayaan melalui Hibah Program Pengembangan Desa Mitra (PPDM) tahun anggaran 2020. Ucapan terimakasih juga buat LP2M Universitas Flores untuk semua fasilitas yang diberikan selama kegiatan ini berlangsung

\section{DAFTAR PUSTAKA}

Asmaliyah, A., \& Rostiwati, T. (2015). Pengaruh pengaturan jarak tanam terhadap perkembangan serangan hama dan penyakit pulai darat (Alstonia angustiloba). Jurnal Penelitian Hutan Tanaman, 12(1), 41-50. https://doi.org/10.20886/jpht.2015.12.1.4 $1-50$

Azima, S., Syahribulan, Sjam, S., \& Santosa, S. (2017). Analisis keragaman jenis serangga predator pada tanaman padi di areal persawahan Kelurahan Tamalanrea Kota Makassar. Bioma: Jurnal Biologi Makassar, 2(2), 12-18. https://doi.org/10.20956/bioma.v2i2.2042

Effendi, R., Salsabila, H., \& Malik, A. (2018). Pemahaman tentang lingkungan berkelanjutan. Modul, 18(2), 75-82. https://doi.org/10.14710/mdl.18.2.2018.7 5-82

Herlinda, S., Waluyo, Estuningsih, S, \& Irsan, C. (2008). Perbandingan keanekaragaman spesies dan kelimpahan arthropoda predator penghuni tanah di sawah lebak yang diaplikasi dan tanpa aplikasi insektisida. Jurnal Entomologi Indonesia, 5(2), 96-107.

Ibrahim, E., Fahmi, D. A., \& Suryana, Y. (2019). Tingkat pengetahuan, sikap dan perilaku petani dalam pengelolaan konservasi musuh alami sebagai upaya pengendalian tungro di Kalimantan Selatan. Jurnal Lahan Suboptimal, 7(2), 121-127. https://doi.org/10.33230/jlso.7.2.2018.35 2

Mutiara, C., \& Bolly, Y. Y. (2019). Identification of agricultural activities and soil fertility in the cultivation area of nuabosi cassava. Caraka Tani: Journal of 
Sustainable Agriculture, 34(1), 22-30. https://doi.org/10.20961/carakatani.v34i1 .25708

Nuha, M. U., Fajriani, S., \& Arifin. (2015). Pengaruh aplikasi legin dan pupuk kompos terhadap hasil tanaman kacang tanah (Arachis hypogaea L.) varietas jerapah. Jurnal Produksi Tanaman, 3(1), 75-80.

Nurindah. (2006). Pengelolaan agroekosistem dalam pengendalian hama. Perspektif: Review Penelitian Tanaman Industri, 5(2), 78-85.

PemdaEnde. (2017). (RKPD).

Purnomo, J. (2014). Pengaruh bahan organik dan pola tanam terhadap produktivitas typic kanhapludult. Prosiding Seminar Hasil Penelitian Tanaman Aneka Kacang dan Umbi, 859-866.

Roidah, I. S. (2013). Manfaat penggunaan pupuk organik untuk kesuburan tanah. Jurnal Bonorowo, 1(1), 30-43.

Siagian, L., Wilyus, \& Nurdiansyah, F. (2019). Penerapan pola tanam tumpangsari dalam pengelolaan hama tanaman kacang hijau (Phaseolus radiatus L.). Journal Agroecotania, 2(2), 32-42. https://doi.org/10.22437/agroecotania.v2i 2.8739

Sulle, A. (2008). Pengaruh kesuburan tanah terhadap penyakit blendok pada pertanaman jambu mete. Jurnal Perlindungan Tanaman Indonesia, 14(2),
70-75.

Syarief, M., \& Tripama, B. (2013). Pengaruh pengelolaan hama berbasis ekologis terhadap keanekaragaman musuh alami dan tingkat serangan Crocidolomia pavonana Zell. (Lepidoptera: Pyralidae). Agritrop Jurnal Ilmu-Ilmu Pertanian, 12(1), 50-54.

Wahyunto, \& Dariah, A. (2014). Degradasi lahan di Indonesia: Kondisi existing, karakteristik, dan penyeragaman definisi mendukung gerakan menuju satu peta. Jurnal Sumberdaya Lahan, 8(2), 81-93.

Wardani, N. (2017). Perubahan iklim dan pengaruhnya terhadap serangga hama. Prosiding Seminar Nasional Agroinovasi, 1015-1026.

Wijanarko, A., Taufiq, A., \& Rahmianna, A. (2009). Pengaturan jarak tanam ubikayu dan kacang tanah untuk meningkatkan indeks pertanaman di lahan kering masam Banjarnegara. Balai Penelitian Tanaman Aneka Kacang dan Umbi. https://balitkabi.litbang.pertanian.go.id/in fotek/pengaturan-jarak-tanam-ubikayudan-kacang-tanah/

Wulandari, R. (2016). Metode kunjungan lapangan untuk menanamkan kepedulian terhadap lingkungan hidup. Pedagogia: Jurnal Pendidikan, 5(1), 67-80. https://doi.org/10.21070/pedagogia.v5i1. 90 